\title{
FACULDADE DE CIÊNCIAS ADMINISTRATIVAS DE CURVELO: corpo discente e docente e matriz curricular (1991-1994)
}

\author{
Bruno Anthony Gonçalves MENEZES ${ }^{1}$ \\ Flávio César Freitas VIEIRA ${ }^{2}$
}

\begin{abstract}
Resumo
Esta pesquisa na área da História da Educação teve o objetivo geral de compreender o processo de implantação da Faculdade de Ciências Administração de Curvelo, no Estado de Minas Gerais (MG), no período de 1991 a 1995. Nesse sentido, de maneira específica, visa a delimitação do perfil discente, suas origens territoriais e sociais, a caracterização do corpo docente quanto aos aspectos relativos à sua formação, profissional e acadêmica, bem como a matriz curricular implantada, inicialmente, no curso de Administração, criado em 1990, com o ingresso da primeira turma, em 1991. A metodologia utilizada foi a Pesquisa Documental, com fontes primárias e secundárias obtidas nos arquivos da Mitra Arquidiocesana de Diamantina, na legislação pertinente, bem como em fontes bibliográficas da área de história da educação. A partir desta pesquisa foi possível compreender o perfil dos alunos, dos professores, bem como a matriz curricular, de maneira a estabelecer um panorama institucional dos primeiros anos de funcionamento da instituição na cidade de Curvelo, MG.
\end{abstract}

Palavras-chave: História de Instituição Educativa. Corpo Discente. Corpo Docente. Matriz Curricular.

\footnotetext{
${ }^{1}$ Mestre em Educação pelo Programa de Pós-Graduação em Educação (PPGEd) da Universidade Federal dos Vales do Jequinhonha e Mucuri (UFVJM); Integrante do Grupo de Estudos e Pesquisas Sócio Históricas em Educação dos Vales (GEPSHE) e professor do Curso de Administração da Faculdade de Administração de Curvelo, Curvelo, MG.

E-mail: bramenezes@yahoo.com.br

2 Doutor em Educação pelo Programa de Pós-Graduação em Educação (PPGED) da Universidade Federal de Uberlândia (UFU). Integrante do Grupo de Estudos e Pesquisas Sócio Históricas em Educação dos Vales (GEPSHE). Professor do Curso de Pedagogia e do PPGEd da UFVJM, Diamantina, MG.

E-mail: flavio.cesar36@gmail.com
} 


\title{
FACULTY OF ADMINISTRATIVE SCIENCES OF CURVELO: Student and teaching staff and curricular matrix (1991-1994)
}

\author{
Bruno Anthony Gonçalves MENEZES \\ Flávio César Freitas VIEIRA
}

\begin{abstract}
This research project on the History of Education had as its main objective to comprehend the implementation of the Curvelo School of Business, in the state of Minas Gerais, between 1991 and 1995. For this purpose, specifically, it aims for a delineation of its student's profiles, its social and territorial origins, a description of its faculty regarding their qualification, both professional and academic, as well as the curriculum initially implemented for the Business course, which was created in 1990 and whose first class started in 1991. The methodological framework is Documental Research, with primary and secondary sources obtained in the archives of the Diamantina Archdiocesan Miter, in the relevant legislation, as well as in bibliographical sources in the fields of the history of education. This research enables a comprehension of the profiles of students, professors and the curriculum, so as to establish an institutional overview of the first years of the institution in the city of Curvelo, Minas Gerais.
\end{abstract}

Keywords: History of Educational Institution. Student body. Faculty. Curriculum. 


\section{Introdução}

Este estudo é um objeto do campo investigativo da história da educação, com foco no desvelamento da história da Faculdade de Ciências Administrativas de Curvelo, no Estado de Minas Gerais (MG), em seu primeiro ano de funcionamento, a partir da descrição do primeiro currículo implantado, do perfil e da origem dos alunos que ingressaram na primeira turma, bem como o perfil dos professores que desempenharam suas funções na instituição nos primeiros quatro anos de funcionamento: de 1991 a 1994. O objetivo, assim, foi traçar um panorama da instituição nos anos posteriores à sua criação.

Trata-se do estudo de uma Faculdade criada pela Mitra Arquidiocesana de Diamantina, entidade pertencente à Igreja Católica, proprietária do Colégio Padre Curvelo, que teve suas origens como Liceu Mineiro, no ano de 1927 e que, a partir de sua estrutura organizacional e física, serviu de base para criação do primeiro curso de Administração de Empresas e da referida Faculdade, em Curvelo, na região Centro-Norte de Minas Gerais.

A sustentação bibliográfica para o desenvolvimento deste artigo foi estabelecida com base nas referências de Magalhães (2004), Nóvoa (1991), Gatti Jr. e Oliveira (2002) e Buffa e Nosella (2002). As fontes da pesquisa foram levantadas nos arquivos da Faculdade de Ciências Administrativas de Curvelo, onde foram localizados os documentos que puderam estabelecer o perfil dos primeiros alunos que ingressaram na instituição, origem social e regional, o currículo dos professores, bem como a primeira matriz curricular implantada no curso.

A partir dessa investigação sobre a Faculdade, foi possível compreender a realidade local atingida pela implantação da instituição, assim como compreender a realidade regional e sua conexão com a nacional, uma vez que a escola estava submetida a diretrizes e procedimentos legais de ordem federal e acompanhou as tendências apontadas por avaliadores designados pelo Ministério da Educação acerca das condições de sua implantação.

A seção 2 deste artigo trata das questões referentes ao corpo discente, suas origens territoriais e sociais, bem como traz para a discussão e reflexão os parâmetros estabelecidos de modo a justificar a criação de um curso superior em Administração na região, considerando, para isso, todos os possíveis interessados em realizar um curso superior. Porém, foi detectado que entre os alunos, em sua maioria eram advindos de escolas particulares e concretizaram o ingresso na instituição.

A seção 3 expõe o perfil dos professores que primeiro atuaram na instituição, com formação em diversas do Estado de Minas Gerais. Considera a relevância institucional e social como espaço profissional para o desempenho da atividade dos professores de MG. Foram detalhadas as instituições de formação dos professores, cursos, bem como os programas que foram desenvolvidos pela Faculdade na década de 1990, de auxílio financeiro para realização de capacitações pelo seu corpo docente. 
A seção 4 descreve as características de composição da matriz curricular, especificando as fundamentações legais que estabeleceram a maior parte das disciplinas do currículo, bem como a participação da instituição e da comissão avaliadora do MEC na definição conjunta da matriz curricular, levando em consideração aspectos regionais que sinalizavam como uma necessidade o aprimoramento do comércio.

Dessa maneira, com base nas seções aqui descritas, é possível conhecer os primeiros anos de funcionamento da instituição, em suas dimensões curriculares e seus corpos docente e discente.

\section{O corpo discente e suas origens territoriais e sociais}

A autorização para a criação do curso de Administração na cidade de Curvelo foi influenciada diretamente pela ausência, em seu território e região de abrangência, de cursos superiores, sobretudo em Administração de Empresas, de acordo com os apontamentos destacados na “Carta Consulta” aprovada pelo Ministério da Educação, referente à autorização do curso. Nessa vertente, o Município tornou-se polo central de atendimento da região centro norte do Estado de Minas Gerais, enquanto precursor na criação de oportunidade de acesso ao nível superior.

A delimitação geográfica para a atuação institucional foi subdividida em três etapas. A primeira trata do território inicialmente estabelecido para a criação do curso, região delimitada em sua abrangência de atendimento educacional e nomeada Distrito GeoEducacional 17, com cerca de 125 municípios em sua abrangência, esse distrito abarcava cidades, a partir de Curvelo, que se encontram na região central do Estado de Minas Gerais, estendendo-se até parte da região norte de Minas e do Vale do Jequitinhonha.

A segunda análise da abrangência de atendimento foi estabelecida a partir de dados coletados no primeiro vestibular e caracteriza o perfil dos interessados na realização do curso, suas características sociais e econômicas, no ano de 1991.

Na terceira etapa, foram levantadas informações sobre a primeira turma que concluiu o curso superior em Administração de Empresas, no ano de 1994. Trata-se de um refinamento de buscas sobre os discentes que efetivamente concluíram a graduação, em sua primeira turma, levantando onde cursaram o ensino médio e à qual região geográfica procediam.

A primeira etapa de demarcação geográfica foi na fase inicial de criação do curso, com a aprovação da "Carta Consulta”, e a principal justificativa foi a de suprir a carência de oferta de cursos no Distrito Geo-Educacional 17, que engloba os municípios de:

Itacaranbi, Januária, Montalvânia, São Francisco, Espinosa, Mato Verde, Monte Azul, Porteirinha, Riacho dos Macacos, Águas Vermelhas, Rio Pardo de Minas, Rubelita, Salinas, S. João do Paraíso, Taiobeiras, Arinos, Bonfinópolis de Minas, Buritis, Formoso, GuardaMór, João Pinheiro, Lagamar, Paracatu, Presidente Olegário, Unaí, Vazante, Buritizeiro, Pirapora, Santa Fé de Minas, São Romão, 
Bocaiuva, Brasília de Minas, Capitão Enéas, Claro dos Poções, Coração de Jesus, Engenheiro Navarro, Francisco Dumont, Francisco Sá, Ibiá, Janaúba, Jequitaí, Juramento, Lagoa dos Patos, Mirabela, Montes Claros, São João da Ponte, Ubaí, Varzelândia, Botumirim, Cristália, Grão Mogol, Itacambira, André Fernandes, Araçuaí, Caraí, Comercinho, Cel. Murta, Itaobim, Itingá, Medina, Novo Cruzeiro, Padre Paraíso, Pedra Azul, Virgem da Lapa, Almenara, Bandeirinha, Felisburgo, Jacinto, Jequitinhonha, Joaíma, Jordânia, Rio do Prado, Rubim, Salto da Divisa, Santa Maria do Salto, Santo Antônio do Jacinto, Augusto de Lima, Buenópolis, Corinto, Curvelo, Inimutaba, Joaquim Felício, Lassance, Monjolos, Morro da Garça, Presidente Juscelino, Santo Hipólito, Várzea da Palma, Berilo, Capelinha, Carbonita, Chapada do Norte, Couto de Magalhães de Minas, Datas, Diamantina, Felício dos Santos, Felisberto Caldeira, Francisco Badaró, Gouveia, Itamarandiba, Minas Novas, Presidente Kubitschek, Senador Modestino Gonçalves, Serro, Turmalina, Arapuá, Carmo de Paraíba, Guimarânia, Lagoa Formosa, Matutina, Patos de Minas, Rio Paranaíba, São Gonçalo do Abaeté, São Gotardo, Tiros, Abaeté, Barreira Grande, Biquinhas, Cedro do Abaeté, Felixlândia, Martinho Campos, Morada Nova de Minas, Paineiras, Pompeu e Quartel Geral. (BRASIL, SEAC; Ofício..., 1986, s.n.).

No total, o Distrito Geo-Educacional 17 contava com 125 municípios que, em 1987, abrigava somente um curso de Administração com 50 (cinquenta) vagas, o que demonstrava a ausência de cursos superiores nesse distrito. Com a descrição da região que motivou a criação da instituição, é possível afirmar que a região Centro-Norte do Estado, composta, na definição da Fundação João Pinheiro (1999, p. 65), por “(Noroeste, Norte, Jequitinhonha, Vale do Mucuri e Central Mineira) e três microrregiões (Sete Lagoas, Conceição do Mato Dentro; e Pará de Minas) [...], caracteriza-se por uma menor expressão econômica em comparação com as demais áreas do Estado”.

Nesse contexto de limitações econômicas e sociais, a educação pode ser vista como uma possibilidade de melhorias:

\begin{abstract}
Nos planos social e individual e nas suas diferentes modalidades, informativa e formativa, formal e informal, simbólica, atitudinal, profissional, cívica, constitui uma preocupação, um desafio e uma ação de humanização e singularização. Mas, na sua vertente sócio comunitária, a educação funciona também como uma estratégia de desenvolvimento, integração, reconhecimento e consolidação de uma cidadania e de uma identidade municipais. (GONÇALVES NETO; MAGALHÃES, 2009, p.06)
\end{abstract}

Diante do contexto regional de uma limitação econômica maior do que o de outras regiões, o que sugerem Gonçalves Neto e Magalhães (2009), no que se refere à educação, enquanto estratégia de desenvolvimento, enquadra-se na realidade em discussão e essa tônica foi determinante para a abertura do curso de Administração no território de Curvelo, pertencente à região Centro-Norte de Minas Gerais, pois a falta de acesso ao ensino de nível superior, no final dos anos de 1980 e início da década de 1990, foi mais um dificultador no que tange às possibilidades de ascensão social e melhoria da qualidade de vida das pessoas desta região.

A segunda etapa de análise do território foi elaborada a partir do público-alvo institucional, ou seja, dos alunos que participaram do primeiro vestibular. Para esse estudo, foi avaliado o trabalho desenvolvido por Buffa e Nosella (2002) sobre a Schola Mater. 
Nessa pesquisa, os autores, ao descreverem os discentes, apresentam as seguintes características que auxiliaram na busca por fontes e na descrição do perfil discente da Faculdade de Ciências Administrativas de Curvelo: 1) Dados do vestibular referentes ao número de candidatos por vaga; 2) Documentação apresentada para ingresso; 3) Sexo; 4) Classe social; e 5) Destino pretendido.

Foram ainda analisados aspectos sociais descobertos nos documentos referentes aos alunos. Vale destacar que as categorias observadas no trabalho de Buffa e Nosella (2002) foram utilizadas, neste estudo, como fonte de inspiração e não de maneira a engessar a pesquisa, tendo em vista a realidade específica da Faculdade de Ciências Administrativas de Curvelo/MG.

Em 1991, concorreram ao exame vestibular 248 alunos, para um total de 50 vagas ofertadas, o que gerou uma demanda de 4,96 candidatos por vaga, e o total de 50 matrículas efetivadas. (MITRA, Relatório do Vestibular... 1991)

Os dados referentes aos vestibulandos foram subdivididos em: situação empregatícia; local de residência; se detinham ensino de segundo grau profissionalizante; se possuíam curso de $3^{\circ}$ grau e se a renda era superior a um salário mínimo. Os dados foram obtidos a partir do documento da MITRA, intitulado "Relatório do Vestibular do ano de 1991 da Faculdade de Ciências Administrativas de Curvelo”, localizado nos arquivos da instituição, conforme dados compilados no Quadro 01, abaixo:

Quadro 01 - Perfil dos vestibulandos do ano de 1991 do curso de Administração de Empresas

\begin{tabular}{|c|c|c|c|c|}
\hline PERFIL DOS & RESPOSTA & UNIDADE & \% UNITÁRIO & \multirow{2}{*}{ \% TOTAL } \\
\hline \multirow{2}{*}{ VESTIBULANDOS } & Sim & 184 & $74 \%$ & \multirow{2}{*}{$100 \%$} \\
\hline \multirow{2}{*}{ Residiam em Curvelo } & Não & 65 & $26 \%$ & \\
\cline { 2 - 4 } & Sim & 170 & $69 \%$ & \multirow{2}{*}{$100 \%$} \\
\hline \multirow{2}{*}{$\begin{array}{c}\text { Detentores de Curso de } \\
2^{\circ} \text { grau profissionalizante }\end{array}$} & Não & 75 & $31 \%$ & \multirow{2}{*}{$100 \%$} \\
\hline \multirow{2}{*}{$\begin{array}{c}\text { Já possuíam curso de 3 } \\
\text { Grau? }\end{array}$} & Sim & 164 & $66 \%$ & \multirow{2}{*}{$100 \%$} \\
\cline { 2 - 4 } & Sim & 13 & $5 \%$ & \multirow{2}{*}{$100 \%$} \\
\hline $\begin{array}{c}\text { Renda familiar maior ou } \\
\text { menor que um salário } \\
\text { mínimo }\end{array}$ & Mais que um salário & 225 & $0 \%$ & \\
\cline { 2 - 4 } & Menos de um salário & 0 & $100 \%$ & \\
\hline
\end{tabular}

Fonte: Elaborado pelo autor a partir de Relatório do Vestibular Mitra, 1991.

Referente à situação empregatícia, foi observado que cerca de 74\% dos interessados trabalhavam e $26 \%$ não trabalhavam. Dessa forma, é possível afirmar que era grande a busca por maior qualificação, sobretudo dos que já exerciam atividade laborativa, associando o curso, diretamente, ao desenvolvimento profissional. 
Quanto ao aspecto relativo à região de origem dos candidatos, constatou-se que 69\% residiam em Curvelo e que 31\% eram de outras cidades. Salienta-se que o relatório não especifica as cidades onde nasceram. Esse fato demonstra que, embora a Faculdade tenha sido criada com o objetivo de atender a uma vasta demanda regional, efetivamente, o município de Curvelo foi o mais beneficiado naquele ano.

Concernente ao grau de formação, verificou-se que 66\% dos alunos eram detentores de formação técnica, o que permite estabelecer correlação direta entre o curso de Administração e o perfil dos interessados como pessoas que já tinham uma formação profissionalizante e que procuravam o curso superior para dar prosseguimento aos estudos.

Constatou-se, ainda, que somente $5 \%$ dos interessados em realizar o vestibular possuíam curso superior, o que demonstra a demanda inicial por formação superior dos alunos que ali se preparavam para o ingresso na instituição.

Ao avaliar o requisito renda, foi constatado que todos os interessados em fazer o exame de vestibular possuíam rendimento familiar superior a um salário mínimo. Tal fato explicita a avaliação indicativa da necessidade de políticas públicas no intuito de oferecer aos mais desfavorecidos a oportunidade de acesso ao ensino superior.

Observa-se, também, que o relatório referente ao primeiro vestibular foi limitador na análise quanto ao quesito renda, pois apurava somente a informação de que os alunos possuíam renda familiar maior ou menor que um salário mínimo. Esse fato não é esclarecedor, por completo, pois, para a categorização da classe econômica, seria necessário conhecer as faixas de renda que extrapolam o salário mínimo, permitindo estabelecer comparações com outros indicadores oficiais, e que, neste caso, deixou de fornecer o subsídio necessário à análise e definição das classes sociais.

Salienta-se que, por correlação, é possível identificar que a maioria da clientela do curso era derivada de classes melhor estabelecidas financeiramente. Tal situação está associada à mensalidade cobrada na primeira parcela de 1991, no valor de Cr\$ 18.480,00 (dezoito mil, quatrocentos e oitenta cruzeiros), que era superior ao salário mínimo que, no mês de fevereiro de 1991, valia “Cr\$ 15.895,46 (quinze mil, oitocentos e noventa e cinco cruzeiros e quarenta e seis centavos)” (UFU-UNIVERSIDADE, Salário..., 2017).

Destarte, a partir dos dados apresentados, tendo em vista que não havia nenhum tipo de política pública implementada para o oferecimento de bolsa de estudos ou financiamento estudantil, na instituição, no ano de criação do curso, verifica-se que o acesso ao curso superior de Administração foi limitado à pequena fatia da população que gozava de melhores condições financeiras.

Conforme pôde ser analisado, embora a criação institucional tenha sido motivada pela demanda social regional para criação de cursos no Distrito Geo-Educacional 17, as classes sociais menos favorecidas tinham poucas chances de acesso, no ano da implantação da Faculdade. Esses fatos sugerem a necessidade de estratificação da real demanda de 
alunos a serem atendidos quando da criação de um curso superior, bem como o estabelecimento de políticas públicas que criem condições de acesso, de maneira igual a todos os interessados.

A terceira etapa define o perfil discente e delimita o território efetivamente beneficiado com o curso, no primeiro ano de sua implantação. Foi realizado um estudo com os dados dos alunos que ingressaram no primeiro vestibular, em 1991, demonstrando que, do total de 50 (cinquenta) ingressantes, 35 (trinta e cinco) concluíram o curso de graduação, no ano de 1994, sendo 22 (vinte e dois) do sexo feminino e 13 (treze) do sexo masculino.

Na definição do território e do perfil dos alunos concluintes, foi verificado que 66\% nasceram em Curvelo, 6\% em Belo Horizonte, 6\% em Corinto, e as cidades de Andrequicé, Campo Azul, Montes Claros, Morro da Garça, Ouro Preto, Pedro Leopoldo e Pirapora, em conjunto, somavam $21 \%$ dos discentes.

É possível definir que 85\% dos alunos que concluíram o curso na primeira turma da instituição eram naturais do Distrito Geo-Educacional 17, e que foram atendidos, principalmente, estudantes que nasceram em Curvelo.

Quanto ao dado referente à residência dos alunos, foi constatado que, no momento do ingresso na Faculdade, 89\% residiam em Curvelo, 6\% em Corinto, 3\% em Várzea da Palma e 3\% em Inimutaba. Esse fato caracteriza o processo de migração para Curvelo, pois para estudar fazia-se necessária a permanência no Município ou em cidade próxima.

Ao analisar essas informações, percebeu-se a necessidade de avaliação do nível de escolarização dos discentes em fase anterior à graduação, bem como o local onde eles o cursaram. O resultado, descrito no Quadro 02, a seguir, partiu de informações relativas ao nome da escola, onde estava situada e se a instituição escolar era pública ou privada:

\section{Quadro 02 - Perfil dos alunos por cidade, escola de conclusão do $2^{\circ}$ grau e tipo de ensino anteriormente cursado, público ou privado.}

\begin{tabular}{|c|c|c|c|c|}
\hline CIDADE & $\begin{array}{c}\text { COLÉGIO ONDE } \\
\text { CONCLUÍRAM O } 2^{\circ} \\
\text { GRAU }\end{array}$ & QUANTIDADE & PERCENTUAL & $\begin{array}{l}\text { PÚBLICA/ } \\
\text { PRIVADA }\end{array}$ \\
\hline Curvelo & Padre Curvelo & 16 & $46 \%$ & Privada \\
\hline Curvelo & Instituto Santo Antônio & 5 & $14 \%$ & Privada \\
\hline Curvelo & $\begin{array}{c}\text { Escola Estadual Bolivar } \\
\text { de Freitas }\end{array}$ & 5 & $14 \%$ & Pública \\
\hline Curvelo & $\begin{array}{l}\text { E.Estadual Ministro } \\
\text { Adalton Lúcio Cardoso }\end{array}$ & 1 & $3 \%$ & Pública \\
\hline Bambuí & E.Agrícola de Bambuí & 1 & $3 \%$ & Pública \\
\hline $\begin{array}{c}\text { Belo } \\
\text { Horizonte }\end{array}$ & $\begin{array}{l}\text { Colégio Integral } \\
\text { Promove }\end{array}$ & 1 & $3 \%$ & Privada \\
\hline Corinto & Instituto Dom Serafim & 1 & $3 \%$ & Privada \\
\hline Corinto & $\begin{array}{c}\text { E.E.Brígido Pereira } \\
\text { Pedras }\end{array}$ & 1 & $3 \%$ & Pública \\
\hline
\end{tabular}




\begin{tabular}{|c|c|c|c|c|}
\hline $\begin{array}{c}\text { João } \\
\text { Pinheiro }\end{array}$ & Colégio Frei Dionísio & 1 & $3 \%$ & Pública \\
\hline $\begin{array}{c}\text { Montes } \\
\text { Claros }\end{array}$ & $\begin{array}{c}\text { Centro Educacional } \\
\text { Montes Claros }\end{array}$ & 1 & $3 \%$ & Privada \\
\hline Ouro Preto & $\begin{array}{c}\text { E.Ténica Federal de } \\
\text { Ouro Preto }\end{array}$ & 1 & $3 \%$ & Pública \\
\hline $\begin{array}{c}\text { Pedro } \\
\text { Leopoldo }\end{array}$ & $\begin{array}{c}\text { E.E. Imaculada } \\
\text { Conceição }\end{array}$ & 1 & $3 \%$ \\
\hline
\end{tabular}

Fonte: Elaborado pelo autor a partir de documentos constantes na Caixa de Arquivos dos formandos (MITRA, 1995)

A partir dos dados destacados no quadro acima, é possível perceber que a Faculdade recebeu alunos de 7 (sete) cidades: Curvelo com 77\%, Corinto com 6\% e as demais: Bambuí; Belo Horizonte; João Pinheiro; Montes Claros; Ouro Preto; e Pedro Leopoldo, somando 17\%. Dessas cidades, 12 (doze) escolas foram representadas, conforme pode ser observado na segunda coluna do Quadro 02, acima.

Destaca-se que, de todas as escolas das quais os alunos eram oriundos, o Colégio Padre Curvelo representou a maioria, com $46 \%$ do total de discentes concluintes do curso superior em Administração, seguida do Instituto Santo Antônio, com 14\%, e a Escola Estadual Bolivar de Freitas, também com 14\%. Essas três unidades escolares representaram a origem de $74 \%$ dos alunos formados. Ao comparar tais dados com os números derivados do vestibular, quando foi estabelecida a relação de 4,58 candidatos por vaga, observa-se que essas escolas três destacaram-se na preparação de seus alunos, obtendo melhor resultado final.

Outro ponto que merece atenção refere-se à origem dos discentes, do ponto de vista da rede de ensino, entre pública e privada. Do total de egressos, 69\% vieram de Colégios Particulares, o que demonstra que a preparação e o acesso eram mais favoráveis às classes que detinham mais condições para investir na educação, desde o ensino médio.

Destaca-se, ainda, que os alunos do Colégio Padre Curvelo representavam uma fatia significativa do público da nova instituição criada, o que fortalece a ideia de Magalhães (2004), de que as escolas são organismos em constante modificação e, neste caso, a Faculdade foi criada para atender, inicialmente, a demanda derivada do próprio Colégio que a originou.

A partir dos dados apresentados, faz-se relevante a sua associação aos dados da pesquisa publicada pelo IPEA, alusiva ao ensino superior na década de 1990, em que lista uma série de limitações de acesso ao ensino, desde a renda até os problemas sociais, como o trabalho infantil:

Entretanto, a ampliação da oferta de vagas não constitui condição suficiente para assegurar a democratização do acesso ao ensino superior, na medida em que o processo de seleção (de caráter discriminatório) tem início muito antes do momento em que se realizam os exames vestibulares, em geral, ditado pela desigualdade de renda entre as famílias, que implica diferenciadas oportunidades de acesso à educação básica, assim como distintos graus de envolvimento 
e dedicação aos estudos (a incidência do trabalho infantil, por exemplo). (BORBUCCI, 2001, p.107)

Esses elementos apresentados que descrevem a demanda inicial para a criação do curso, o público presente no primeiro vestibular e a população efetivamente atendida pela instituição demonstram a demanda, em escalas regional e local, dos diversos setores sociais por maior atenção por maior atenção com o ensino nos níveis fundamental, médio e superior. Nesta pesquisa, fez-se evidente que os alunos do Colégio Padre Curvelo, e das demais escolas privadas citadas, alcançaram níveis de aproveitamento, no vestibular e na efetiva conclusão do curso, superiores aos dos alunos das escolas públicas de nível médio, que foram, efetivamente, pouco representadas pelo contingente de alunos delas egresso.

\section{O corpo docente}

O corpo docente que ministrou as aulas nos quatro anos da primeira turma de alunos foi composto por graduados, mestres e especialistas, subdividido nas categorias de professores Titulares, Assistentes e Auxiliares de Ensino. Conforme o art. 110, parágrafo único, do Regimento Mitra (1991, p. 49), “entende-se como Professor Titular os responsáveis pelas disciplinas; por Professor Assistente os que auxiliam no ensino de qualquer disciplina; por Auxiliar de Ensino o docente admitido em caráter probatório, por prazo determinado.”

Os professores exerceram papel central enquanto atores no processo de criação da instituição e no desempenho de seus objetivos, pois estavam em contato frequente e direto com os alunos da instituição. Consoante Nóvoa (1996, p. 417), o educador deve ser um profissional capaz de "sentir os desafios do tempo presente, de pensar a sua ação nas continuidades e mudanças do trabalho pedagógico, de participar criticamente na construção de uma escola mais atenta às realidades dos diversos grupos sociais.”

O quadro de docentes era representado por profissionais de diversas áreas do conhecimento e grande parte dos que ministraram aulas para a primeira turma de ingressantes na instituição era diferente em relação ao conjunto dos professores aprovados nas etapas de criação do curso. No Quadro 03, abaixo, vêm indicados aqueles que proferiram aulas para a primeira turma:

\section{Quadro 03 - Professores por ano/série/disciplina}

\begin{tabular}{|c|c|c|}
\hline ANO/SÉRIE & DISCIPLINA & PROFESSOR \\
\hline \multirow{4}{*}{$1991 / 1^{\text {a }}$ série } & Contabilidade I & José Maria da Silva \\
\cline { 2 - 3 } & $\begin{array}{c}\text { Instituições de Direito Público e } \\
\text { Privado }\end{array}$ & $\begin{array}{c}\text { Marcus Vinicius Guimarães de } \\
\text { Freitas }\end{array}$ \\
\cline { 2 - 3 } & Matemática & Verá Lúcia Corrêa da Silva \\
\cline { 2 - 3 } & $\begin{array}{c}\text { Sociologia Aplicada à } \\
\text { Administração }\end{array}$ & Geraldo Rodrigues Álvarez \\
\hline
\end{tabular}




\begin{tabular}{|c|c|c|}
\hline & Teoria Econômica & João de Oliveira Júnior \\
\hline & Teoria Geral da Administração & Trajano Arantes de Oliveira \\
\hline & Educação Física & Eloiza Helena Pereira \\
\hline \multirow{7}{*}{ 1992/ 2a série } & Contabilidade II & José Maria da Silva \\
\hline & Economia Brasileira & José Israel Rodrigues Paraguassu \\
\hline & Estatística I & $\begin{array}{l}\text { Geraldo Márcio de Oliveira e } \\
\text { Silva }\end{array}$ \\
\hline & Legislação Social & $\begin{array}{l}\text { Marcus Vinícius Guimarães de } \\
\text { Freitas }\end{array}$ \\
\hline & Matemática Financeira & Vera Lúcia Corrêa da Silva \\
\hline & Organização \& Métodos & Trajano Arantes de Oliveira \\
\hline & Estudos de Problemas Brasileiros & Márcio Antônio Vita \\
\hline \multirow{8}{*}{ 1993/3a série } & $\begin{array}{l}\text { Administração Financeira e } \\
\text { Orçamento }\end{array}$ & Marcos Lemos Afonso \\
\hline & Administração Mercadológica & Vivaldo Nogueira Batista \\
\hline & Administração de Pessoal & Júlio César da Boa Morte \\
\hline & Controle de Custos & Delmar Pereira de Oliveira \\
\hline & Direito Administrativo & Márcio Antônio Vita \\
\hline & Estatística II & Vera Lúcia Corrêa da Silva \\
\hline & Introdução à Informática & Renato Mudado Silva \\
\hline & $\begin{array}{l}\text { Psicologia Aplicada à } \\
\text { Administração }\end{array}$ & Roberto Pereira da Silva \\
\hline \multirow{6}{*}{ 1994/4 série } & Administração de Material & Nixon Diniz Pereira \\
\hline & Administração da Produção & Reginaldo Vasconcelos Sena \\
\hline & Administração de Vendas & Carla Maria de Moura Melo \\
\hline & Estratégia Empresarial & $\begin{array}{l}\text { Luís Alexandre Simpson do } \\
\text { Amaral }\end{array}$ \\
\hline & Legislação Tributária & $\begin{array}{l}\text { Marcus Vinícius Guimarães de } \\
\text { Freitas }\end{array}$ \\
\hline & Estágio Supervisionado & Antônio Eustáquio Furiati \\
\hline
\end{tabular}

Fonte: Elaborado pelo autor, a partir do Relatório para Reconhecimento do curso

(MITRA, 1994).

No intuito de estabelecer as categorias de análise, no que concerne ao corpo docente, foi avaliado o estudo desenvolvido por Buffa e Nosella (2002) sobre a Schola Mater. Na discussão, os pesquisadores, ao descreverem os docentes, listaram pontos conexos com este trabalho, quanto ao perfil docente, que são: os pressupostos legais para ingresso no cargo, formação acadêmica e o processo de seleção para a carreira.

Na mesma vertente de caracterização do profissional que atuava na carreira docente, Nóvoa cita quatro dimensões que nortearam o levantamento de dados e a pesquisa:

1. Exercer a atividade docente em tempo integral, ou pelo menos, como ocupação principal, não uma atividade passageira, mas sim como um trabalho que ocupa uma parte importante de sua vida profissional;

2. São detentores de uma licença oficial, e para tanto, possuem um suporte legal para o exercício da profissão que confirma a sua condição de profissional do ensino, bem como funciona como instrumento de controle e de defesa da identidade dessa profissão; 
3. Possui uma formação profissional, especializada em instituições apropriadas e destinadas a este fim; e

4. Participam em associações profissionais, que desenvolvem um espírito corporativo na defesa do estatuto dos professores. (NÓVOA, 1991, p.16-17)

A partir das dimensões citadas por Nóvoa (1991), Buffa e Nosella (2002), foram especificados os seguintes aspectos para definição do perfil docente, a partir dos documentos localizados nos arquivos da Faculdade de Ciências Administrativas de Curvelo, bem como da legislação específica que normatizava a atividade docente, em 1991:

1- Exigências legais para ocupação do cargo de professor e regimentais estabelecidos pela instituição;

2- Formação acadêmica dos professores, onde estudaram e quais cursos compunham os currículos;

3- Processo de seleção para ingresso no cargo de professor na instituição.

Não foram localizados documentos que oferecessem dados de maioria significativa dos professores acerca da participação em associações de classe, bem como sobre o exercício da atividade docente em tempo integral. Todavia, em relação aos poucos materiais localizados, o fato de não estabelecerem um nível de confiança estatístico capaz de representar a totalidade do corpo docente institucional, nessas categorias, não permitiu que fossem tratados neste trabalho do ponto de vista metodológico da abordagem qualitativa.

Quanto à categoria 01, que pertence às exigências legais, consoante o art. $6^{\circ}$ da Lei 5.540 de 1968, foi estabelecido que “a organização e o funcionamento dos estabelecimentos isolados de ensino superior serão disciplinados em regimentos, cuja aprovação deverá ser submetida ao Conselho de Educação competente” (BRASIL, 1968). Nessa perspectiva, o regimento institucional aprovado pelo Conselho de Educação descreveu as características referentes ao perfil dos professores da instituição e suas exigências mínimas.

Destarte, o art. 112 do Regimento (MITRA, 1991, p. 50) define que a "qualificação básica e indispensável do docente proposto à admissão necessitava da apresentação de diploma de graduação expedido por curso superior em que haja cursado matéria ou disciplina idêntica ou afim à qual fosse contratado para lecionar.”

A condição mínima para o exercício da atividade docente na instituição foi mencionada no art. 113 do Regimento, considerando aspectos como o nível de titulação, o exercício de atividades técnicas relacionadas à área de atuação e os trabalhos publicados.

Art. 113- A condição mínima para a indicação de professor Titular ou Assistente é a comprovação, pelo indicado, além da qualificação básica indispensável mencionada no art. 112, de:

I- Aproveitamento, em disciplina preponderante de áreas de concentração de curso de Mestrado ou Doutorado, ministrado por instituição idônea, no país ou no exterior, a juízo do Conselho Federal de Educação, com carga horária comprovada de, pelo menos, trezentas e sessenta (360) horas. 
II- Aproveitamento, baseado em frequência e provas, em cursos de Aperfeiçoamento ou Especialização, organizados na forma do art. 59 deste regimento;

III- Exercício efetivo de atividades técnico-profissional, ou de atividade docente de nível superior, comprovada, durante dois (2) anos, no mínimo;

IV- Trabalhos publicados de real valor.

$\S 1^{\circ}$ No caso de professor Titular, o indicado deve preencher, no mínimo, as condições constantes dos itens I ou II concomitantemente com uma das condições indicadas nos itens III ou IV.

$\S 2^{\circ} \mathrm{Na}$ indicação de professor Assistente, o docente deve preencher, no mínimo, uma das exigências constantes dos itens I ou II.

$\S 3^{\circ}$ No caso de matérias profissionais, pode ser indicado à aprovação do Conselho Federal de Educação, em caráter excepcional, professor que comprove além da titulação básica, capacidade técnicoprofissional pertinente, acrescida, no caso de indicação como Titular, de, pelo menos, dois (2) anos de experiência didática em instituições de ensino superior, na matéria ou disciplina respectiva.

$\S 4^{\circ} \mathrm{A}$ exigência de qualificação é considerada como automaticamente atendida no caso de possuir o indicado o grau de Mestre ou Doutor, obtido em curso credenciado com área de concentração concernente à matéria ou disciplina para que foi indicado, ou título de LivreDocente, na área específica. (MITRA, 1991, p.51)

Os pré-requisitos regimentais citados afirmavam a necessidade de que os professores apresentassem, no mínimo, um curso de graduação com disciplina cursada na área de atuação, cursos de especialização e de formação técnico profissional compatível com os conhecimentos práticos exigidos para o desenvolvimento das disciplinas.

Dessa maneira, a carreira docente, na instituição, apresentava como principal aspecto a "titulação", em que os diplomas de Mestrado e Doutorado bastavam para o desempenho das atividades, de maneira plena. No caso da titulação mínima, que era a formação no nível de graduação, era exigida a experiência técnica profissional na área pretendida.

Enquanto autorização legal, todos os professores que ministraram aulas para a primeira turma de ingressantes na instituição foram aprovados para ocuparem os seus cargos por comissão do Ministério da Educação. Desses, os que foram credenciados no processo de criação do curso tiveram a aprovação do Conselho Federal de Educação. Os docentes contratados no decorrer do curso obtiveram a aprovação pelo órgão regional do Ministério da Educação, através da Delegacia do Ministério da Educação do Estado de Minas Gerais.

A autorização pelo órgão responsável garante o atendimento aos critérios legais do exercício da profissão docente na instituição, de acordo com o perfil mínimo estabelecido.

A segunda categoria versa sobre a formação dos professores. Na pesquisa documental realizada no Relatório de Reconhecimento do Curso, de 1994, constatou-se que a maioria dos docentes eram graduados em Administração, conforme descrito na Tabela 01. 
Tabela 1 - Discriminativo do percentual de cursos de graduação dos professores

\begin{tabular}{|c|c|}
\hline GRADUAÇÃo CURSADA & \% DO TOTAL \\
\hline Administração & $32 \%$ \\
\hline Direito & $20 \%$ \\
\hline Economia & $11 \%$ \\
\hline Matemática & $11 \%$ \\
\hline Psicologia & $11 \%$ \\
\hline Contabilidade & $5 \%$ \\
\hline Educação Física & $5 \%$ \\
\hline Engenharia Civil & $5 \%$ \\
\hline Total & $100 \%$ \\
\hline
\end{tabular}

Fonte: Elaborada pelo autor, a partir do Relatório para Reconhecimento do curso (MITRA, 1994).

É possível constatar que, ao comparar a formação dos professores em Administração com as demais áreas do conhecimento que se fizeram presentes na graduação dos docentes, são significativos os percentuais alcançados por áreas diversas, o que caracterizava a diversidade das formações, pois as demais áreas, juntas, somavam 68\% do total, com destaque para a formação em Direito, que contava com 20\% dos professores.

Essa grande proporção de professores de outras disciplinas é justificada pelo currículo que, em sua essência, tinha uma base que apenas no último ano privilegiava as disciplinas técnicas do curso com maior intensidade. O que foi modificado na nova proposta de currículo aprovada em 1993, mas que não surtiu efeitos sobre a primeira turma de ingressantes na instituição. que estava submetida à antiga matriz curricular.

A formação dos professores no nível de graduação ocorreu, em maior intensidade, no Estado de Minas Gerais, o que demonstra a relevância da instituição, no campo profissional, para os professores desse Estado, com menor participação do estado de São Paulo e do Distrito Federal. Ao todo, os professores da Faculdade eram advindos de 13 (treze) instituições, descritas a seguir:

1. Centro de Ensino Unificado de Brasília-DF;

2. Escola Superior de Ciências Contábeis e Administrativas de Ituiutaba-SP;

3. Faculdade de Filosofia, Ciências e Letras de Mogi das Cruzes-SP;

4. Faculdades de Ciências Gerenciais de Belo Horizonte-MG;

5. Faculdade de Direito de Sete Lagoas-MG;

6. Faculdades Integradas de Uberaba-MG;

7. Fundação Mineira de Educação e Cultura de Belo HorizonteFUMEC-MG;

8. Fundação Monsenhor Messias, Sete Lagoas-MG;

9. Universidade Federal de São João Del Rei, UFSJ-MG;

10. Newton Paiva-MG; 
11. Pontifícia Universidade Católica de Minas Gerais, PUC-MG;

12. Universidade Federal de Minas Gerais, UFMG-MG;

13. Universidade Federal de Brasília-DF.

Quanto à pós-graduação, constatou-se que a maioria dos títulos foram obtidos na PUC-MG, no Programa de especialização de Professores do Ensino Superior, nas áreas de Docência do Ensino Superior e com ênfase em Administração. Já na pós-graduação em nível de Mestrado, os professores obtiveram seus respectivos títulos nas Universidades Federais de Lavras, São João Del Rei e Universidade Federal de Minas Gerais, todos em Administração, num total de três professores.

Em geral, constatou-se que, no nível da graduação, os professores advinham de diversas instituições e localidades, o que caracteriza uma preparação do corpo docente com visões institucionais de diferentes escolas e locais do Estado de Minas Gerais e também de outros estados. Quanto aos especialistas, em sua maioria, eram oriundos do programa de formação de Professores da PUC-MG. Já os Mestres, eram todos formados na Rede Federal de ensino.

A formação dos professores ocorreu, em sua maioria, nas décadas de 1970 e 1980, quase a totalidade na rede privada de educação, até o nível de especialização. No que concerne ao nível de Mestrado, os indicadores apontaram para a formação através da rede pública, através das Universidades Federais. Esses professores formados, em sua maioria, na rede privada eram o reflexo da oferta nacional de cursos de Administração no período:

Um dos aspectos que merece ser destacado na expansão dos cursos de administração é a considerável participação na rede privada nesse processo, ocorrido a partir do final dos anos 70 . No início da década de 1980, o sistema particular era responsável por aproximadamente $79 \%$ dos alunos, ficando o sistema público com o restante. O mesmo ocorre com as demais áreas do conhecimento, em que a distribuição é de $61 \%$ para a rede privada. (AMBONI; ANDRADE, 2004, p. 09)

Em relação à formação profissional, houve a contratação de profissionais com experiência técnica na área administrativa e com atuação na carreira docente. Observa-se, ainda, que parte do quadro de professores do Colégio Padre Curvelo, advindos das áreas de Matemática, Educação Física, Filosofia e História, foram aproveitados na instituição.

Na terceira categoria, referente ao processo de contratação dos professores, foi detectado que a instituição adotava o mecanismo da indicação, como método de recrutamento dos candidatos, e de entrevista e avaliação pelo conselho departamental, para selecioná-los, conforme estabelecido em Regimento institucional. Após a aprovação do Conselho Departamental, titulares e assistentes subordinavam-se à aprovação do Conselho Federal de Educação ( MITRA, 1991).

A maneira como o processo de seleção era desenvolvido não foi descrito em suas especificidades no regimento. Dessa maneira, ficava a cargo do Diretor, com a avaliação criteriosa do conselho departamental, a aprovação do professor relativa à análise das 
habilidades de condução da disciplina e dos pré-requisitos estabelecidos nos art. 112 e 113 do Regimento da entidade mantenedora.

Foi mencionada, no Relatório para Reconhecimento do Curso (1994), a preocupação da instituição com o processo de seleção dos professores, bem como com a política de formação continuada do corpo docente.

\begin{abstract}
A Faculdade se preocupa principalmente com a contratação de professores portadores de, no mínimo, curso de pós-graduação lato sensu, procurando recrutar ainda, nas disciplinas do ciclo profissional, profissionais de notório conhecimento e experiência e com condições efetivas de desenvolverem atividades magisteriais. A política de pessoal, na área de magistério, é o atingimento gradativo do tempo integral. Procura-se, ainda, a identificação de docentes a partir da Monitoria e o estabelecimento de um sistema de qualificação através do financiamento de cursos de aperfeiçoamento e especialização, com garantia de retorno e prestação de serviços de pós-graduado, por tempo mínimo obrigatório. (MITRA, 1994, p.25).
\end{abstract}

Há indícios, conforme apontado no Relatório para Reconhecimento do Curso (MITRA, 1994), de que a instituição, na década de 1990, custeou parte dos gastos dos professores com cursos de especialização e mestrado, como afirmação da aplicação da proposta de desenvolvimento profissional sugerida e que a experiência técnica foi observada no processo de contratação dos professores.

Quanto à formação dos docentes, foi possível constatar que a maioria era composta por especialistas de diversas regiões do Estado, oriundos principalmente de instituições particulares de ensino e cuja maioria residia em Curvelo.

\title{
A matriz curricular
}

O primeiro documento que norteou a criação da matriz curricular fixada para a primeira turma do curso de Administração, que ingressou em 1991, foi a portaria 307/66, aprovada em 08 de julho de 1966 (CONSELHO, 2016). Com base na matriz curricular mínima, a Comissão de Verificação do MEC, em visita in-loco, recomendou a modificação da matriz curricular aos responsáveis pelo projeto do curso.

Essa construção do currículo, a partir de bases legais e das experiências da comissão verificadora e de professores, levou em consideração as especificidades da região de abrangência, que era composta, em sua maioria, por empresas de micro e pequeno porte. A forma como o currículo foi elaborado retrata a realidade da escola na construção de uma unidade de ensino e da matriz curricular, com o objetivo de atender aos interesses da clientela, com matérias de cultura geral, instrumentais e de formação profissional.

No caso da Administração, a metodologia que permite a cada escola conferir organicidade ao estudo de todas as variáveis que interferem no fato administrativo, sejam elas políticas, sociais ou econômicas, em função de seus objetivos, sua história e herança em função das necessidades de sua clientela, deve enfatizar uma sólida formação intelectual que estimule o senso crítico e a mente analítica. [...] Uma estrutura curricular segundo esse senso de organização, envolve um 
trabalho metodológico das matérias de cultura geral, instrumentais e de formação profissional. (AMBONI; ANDRADE, 2004, p. 13)

O Regimento Institucional da MITRA, de 1991, em seu art. 47, apresentou o currículo e a sua definição: “entende-se por currículo o conjunto organizado de disciplinas elaborado para determinado curso”.

Para o conhecimento sobre as disciplinas que compõe o currículo e suas variáveis em termos de normatização legal, criação e apresentação, Gatti Jr. e Oliveira (2002, p. 75) abordam pontos que direcionaram a descrição da matriz curricular da Faculdade de Curvelo: “- qual o currículo que é o normativo e quais são as suas finalidades? - quem os determinam? - que saberes são transmitidos? - como se configuram os programas de ensino? - por que são transmitidos?”

Inicia-se a discussão com base nos primeiros questionamentos dos autores Gatti Jr. e Oliveira (2002) referentes às bases legais do currículo, suas finalidades e quem foram os responsáveis por sua elaboração.

O primeiro currículo mínimo estabelecido para o curso de Administração no Brasil foi aprovado pelo Parecer $n^{\circ}$ 307, de 08 de julho de 1966, que ficou vigente até o ano de 1993, e estabeleceu as disciplinas dos eixos obrigatório e optativo, conforme exposto, abaixo, na Tabela 2:

Tabela 2 - Currículo mínimo do Curso de Administração - fixado em 1969, vigente em 1991

\begin{tabular}{l|l}
\hline DISCIPLINAS DE EIXO OBRIGATÓRIO & DISCIPLINAS OPTATIVAS \\
\hline Matemática, Estatística, Contabilidade, & \\
Teoria Econômica & \\
Economia Brasileira & \\
Psicologia Aplicada à Administração & \\
Sociologia Aplicada à Administração & \\
Instituições de Direito Público e Privado \\
(inclui Noções de Ética Administrativa) \\
Legislação Social & Direito Administrativo \\
Legislação Tributária & Administração de Produção \\
Teoria Geral da Administração & Administração de Vendas \\
Administração Financeira e Orçamento & \\
Administração de Pessoal & \\
Administração de Material. & \\
\hline
\end{tabular}

Fonte: Conselho Federal de Administração, 2016. Adaptado.

A determinação legal do Ministério da Educação direcionava a montagem do currículo pelas instituições de ensino, porém, sobre o primeiro currículo mínimo, poucos estudos foram apresentados na literatura atual. Ao longo da década de 1980, iniciaram-se discussões para a criação de uma nova base curricular que primasse pela adequação do curso ao momento que o país passava, destarte, o currículo que foi implantado estava prestes a ser modificado em escala nacional (MEC/ CFE, 1993). 
O primeiro currículo implantado na instituição foi construído a partir de três bases: o Parecer 307/66, exarado pelo Ministério da Educação, versando sobre o currículo mínimo; as sugestões da Comissão Verificadora in-loco; e as proposições da própria instituição quanto às disciplinas de Educação Física e Estudos de Problemas Brasileiros, através de imposição legal de inserção na matriz, como exposto, por disciplina, na Tabela 3, abaixo:

Tabela 3 - Forma de inserção das disciplinas no currículo em 1991

\begin{tabular}{|c|c|c|}
\hline ANO/SÉRIE & DISCIPLINAS & $\begin{array}{c}\text { FORMA DE DEFINIÇÃO: } \\
\text { LEGAL/INSTITUCIONAL OU } \\
\text { COMISSÃO DE VERIFICAÇÃO }\end{array}$ \\
\hline $1991 / 1^{a}$ & Educação Física & $\begin{array}{c}\text { Definida pelo decreto } 69.450 \text {, de } 1^{\circ} \text { de } \\
\text { novembro de } 1971\end{array}$ \\
\hline $1991 / 1^{\mathrm{a}}$ & $\begin{array}{l}\text { Sociologia Aplicada à } \\
\text { Administração }\end{array}$ & Obrigatória conforme Parecer 307/66 \\
\hline $1991 / 1^{a}$ & Teoria Econômica & Obrigatória conforme Parecer 307/66 \\
\hline $1991 / 1^{\mathrm{a}}$ & Contabilidade I & Obrigatória conforme Parecer 307/66 \\
\hline $1991 / 1^{a}$ & $\begin{array}{l}\text { Instituições de Direito } \\
\text { Público e Privado }\end{array}$ & Obrigatória conforme Parecer 307/66 \\
\hline $1991 / 1^{a}$ & $\begin{array}{l}\text { Teoria Geral da } \\
\text { Administração }\end{array}$ & Obrigatória conforme Parecer 307/66 \\
\hline $1991 / 1^{\mathrm{a}}$ & Matemática & Obrigatória conforme Parecer 307/66 \\
\hline $1992 / 2^{a}$ & $\begin{array}{c}\text { Estudos de Problemas } \\
\text { Brasileiros }\end{array}$ & $\begin{array}{l}\text { Definida pelo decreto 68.065, de } 14 \text { de } \\
\text { janeiro de } 1971 .\end{array}$ \\
\hline $1992 / 2^{a}$ & Matemática Financeira & Definida pela Instituição \\
\hline $1992 / 2^{a}$ & Organização \& Métodos & $\begin{array}{l}\text { Incluída pela Comissão Avaliadora do } \\
\text { MEC }\end{array}$ \\
\hline $1992 / 2^{a}$ & Estatística I & Obrigatória conforme Parecer 307/66 \\
\hline $1992 / 2^{a}$ & Economia Brasileira & Obrigatória conforme Parecer 307/66 \\
\hline $1992 / 2^{a}$ & Contabilidade II & Obrigatória conforme Parecer 307/66 \\
\hline $1992 / 2^{a}$ & Legislação Social & Obrigatória conforme Parecer 307/66 \\
\hline $1993 / 3^{a}$ & Controle de Custos & Definida pela Instituição \\
\hline $1993 / 3^{a}$ & Introdução à Informática & $\begin{array}{l}\text { Incluída pela Comissão Avaliadora do } \\
\text { MEC }\end{array}$ \\
\hline $1993 / 3^{a}$ & $\begin{array}{l}\text { Administração } \\
\text { Mercadológica }\end{array}$ & $\begin{array}{l}\text { Incluída pela Comissão Avaliadora do } \\
\text { MEC }\end{array}$ \\
\hline $1993 / 3^{a}$ & Administração de Pessoal & Obrigatória conforme Parecer 307/66 \\
\hline $1993 / 3^{a}$ & $\begin{array}{c}\text { Administração Financeira e } \\
\text { Orçamento }\end{array}$ & Obrigatória conforme Parecer 307/66 \\
\hline $1993 / 3^{a}$ & $\begin{array}{l}\text { Psicologia Aplicada à } \\
\text { Administração }\end{array}$ & Obrigatória conforme Parecer 307/66 \\
\hline $1993 / 3^{a}$ & Estatística II & Obrigatória conforme Parecer 307/66 \\
\hline $1993 / 3^{a}$ & Direito Administrativo & Optativa conforme Parecer 307/66 \\
\hline $1994 / 4^{a}$ & Estratégia Empresarial & Definida pela Instituição \\
\hline $1994 / 4^{\mathrm{a}}$ & Legislação Tributária & Obrigatória conforme Parecer 307/66 \\
\hline $1994 / 4^{\mathrm{a}}$ & Administração de Material & Obrigatória conforme Parecer 307/66 \\
\hline $1994 / 4^{\mathrm{a}}$ & Estágio Supervisionado & Obrigatória conforme Parecer 307/66 \\
\hline
\end{tabular}




\begin{tabular}{|c|c|c|}
\hline $1994 / 4^{a}$ & Administração de Vendas & Optativa conforme Parecer 307/66 \\
\hline $1994 / 4^{\text {a }}$ & Administração da Produção & Optativa conforme Parecer 307/66 \\
\hline
\end{tabular}

Fonte: Elaborado pelo autor a partir do Relatório para Reconhecimento do Curso (MITRA, 1994) e Decreto 69.450, de 1971.

Ao todo, 28 disciplinas compunham o currículo do curso de Administração. Dessas, 17 (dezessete) eram obrigatórias e 03 (três) optativas, por determinação do Parecer 307/66. Ou seja, 20 matérias estabelecidas pela esfera legal. A disciplina de Educação Física foi incluída no currículo em função do decreto 69.450, de $1^{\circ}$ de novembro de 1971 e a disciplina Estudos de Problemas Brasileiros pelo decreto 68.065, de 14 de janeiro de 1971. Nessa vertente, o currículo apresentou 78\% das disciplinas fixadas por normativos legais.

Verifica-se que as disciplinas Matemática Financeira, Controle de Custos e Estratégia Empresarial foram estabelecidas pela instituição. E que as disciplinas Organização \& Métodos, Introdução à Informática e Administração Mercadológica foram sugeridas pela Comissão Avaliadora in-loco e abarcadas pela instituição, o que resultou no total de $22 \%$ da matriz curricular.

Ficou evidente, assim, que a matriz curricular fora definida com base na legislação, à época, e que havia pouca flexibilidade para modificações e inserções pela instituição.

Quanto à finalidade do currículo, é necessário compreendê-lo como um importante fator de conexão entre os objetivos pretendidos, o ambiente de interação, as empresas, o corpo docente e os alunos, interligando os ideais da disciplina com a filosofia de educação. Torna-se relevante, enquanto proposta, levar o acadêmico a um processo de transformação, como agente de mudanças, de maneira a adaptar-se aos avanços das ciências e da tecnologia. (MEC/ CFE, 1993).

Em resposta ao questionamento “que saberes são transmitidos?”, considera-se que, conforme os dados dispostos na Tabela 3, acima, no primeiro ano do curso, as disciplinas transmitiam conhecimentos sobre matérias de formação geral: Educação Física; Sociologia Aplicada à Administração; Teoria Econômica; Matemática; Contabilidade I; e Instituições de Direito Público e Privado. A disciplina Teoria Geral da Administração era a única alinhada, diretamente, ao objeto de estudo do curso, pretendendo fixar conteúdos sobre as teorias mais modernas das organizações, as estruturas organizacionais, a história e origem das principais ferramentas gerenciais (MITRA, 1994).

No segundo ano, mantém-se a formação geral, com exceção da disciplina Organização e Métodos, que versa sobre as estruturas organizacionais, os fluxos dos processos, a qualidade, bem como sobre inovações e melhorias nos métodos de trabalho. Ao ingressar no terceiro ano, o aluno deparava-se com uma elevada concentração de disciplinas pertencentes à área de Administração. Nesse período, as disciplinas versavam sobre: Controle de Custos nas empresas; Gestão de Pessoas; Finanças; Administração de Marketing; e tecnologias através da Informática (MITRA, 1994). 
No último ano de formação, foram transmitidos saberes sobre as estratégias adotadas pelas empresas, Legislação Tributária, Vendas, Produção e Gestão de Materiais. Enquanto componente de formação prática, é desenvolvida, no último ano, a disciplina Estágio Supervisionado, em que é elaborado um trabalho prático individual sob a orientação de um supervisor, na empresa, e de um professor, na instituição.

Em relação à configuração dos programas de ensino, a instituição estabeleceu, no art. 58 do Regimento (MITRA,1991), que "cada disciplina corresponde a um programa, elaborado pelo respectivo professor sob a forma de plano de ensino aprovado pelo Departamento respectivo no plano setorial, e pelo Conselho Departamental”. Tal proposição diverge do exposto na composição curricular em que a maioria das disciplinas eram estabelecidas pela legislação da época. Quanto ao programa de ensino, havia a possibilidade, mediante aprovação, de que o professor desenvolvesse, com maior flexibilidade, os conteúdos a serem ministrados.

Quanto à última pergunta, que se refere aos motivos pelos quais os conteúdos são transmitidos, com base no exposto, traz o propósito de formar um profissional com os conhecimentos necessários para a adequada administração das instituições, favorecendo a elevação das vendas, a redução de custos e as inovações capazes de promover o crescimento institucional e social através das práticas de Administração de Empresas.

\section{Considerações finais}

No campo da educação superior, poucas foram as alternativas para torná-la uma realidade na região. O curso de Administração estava presente em somente uma cidade pertencente à área de abrangência do Distrito Geo-Educacional 17. Esse fato foi um motivador para a autorização do Ministério da Educação para a criação do curso superior em Administração em Curvelo/MG.

Nessa vertente, a criação do curso foi motivada pelas necessidades da região, de formar profissionais para atuarem na área da Administração, pela carência de cursos superiores e de graduados em nível superior. Em uma escala regional, havia um agravante pelo fato de Curvelo estar inserida na região Centro-Norte do Estado de Minas Gerais, mais castigada que as demais dentro do Estado e que seria beneficiada caso houvesse a implementação de cursos superiores para o desenvolvimento e a melhoria das condições de vida da população.

Quando da criação da instituição, a motivação social caracterizada pela ausência de cursos foi determinante. Essa informação foi confrontada com os dados sobre os alunos ingressantes no primeiro vestibular. Nesta análise, constatou-se que a maioria dos discentes era advinda do Colégio Padre Curvelo, escola de origem dos formandos da primeira turma, que ingressou em 1991, concluindo o curso em 1994. 
Destarte, a justificativa para a criação da Faculdade nas dependências do Colégio Padre Curvelo foi o atendimento à demanda da sociedade de uma ampla região, o distrito Geo-Educacional 17, porém, num primeiro momento, a escola recebeu um enturmamento com a maioria dos alunos derivada do próprio colégio onde se criara a Faculdade e em escolas particulares da própria cidade. Esses fatos são conflitantes com as justificativas para a criação da escola, já que elas não se direcionavam a esse público restrito, efetivamente beneficiado.

O primeiro corpo docente foi composto, em sua maioria, por especialistas com formação em diversas instituições de ensino, com a quase totalidade oriunda do Estado de Minas Gerais. Enquanto experiência profissional, havia docentes com experiência no nível superior e médio de ensino. Esses professores residiam, predominantemente, em Curvelo e, com isso, além de a instituição beneficiar a comunidade local ao oferecer o curso superior, gerou maiores possibilidades de desenvolvimento profissional para os professores que atuavam na região.

O currículo implantado no ano de 1991 foi estruturado, em sua maior monta, a partir de orientações legais estabelecidas nas décadas de 1960 e 1970, composto por disciplinas determinadas pela matriz curricular mínima. Salienta-se, ainda, a colaboração da equipe de avaliadores do Ministério da Educação na elaboração do currículo mínimo e na adequação das disciplinas ao curso pretendido, bem como à realidade regional.

A partir deste estudo, foi possível conhecer um panorama da Faculdade de Ciências Administrativas de Curvelo, com o seu território, seus corpos discente e docente e sua matriz curricular, quando da implantação. Salienta-se a necessidade de análise da demanda social para a criação de cursos superiores, de modo a que sua constituição seja direcionada a diversas classes sociais, sem distinções.

\section{Referências}

AMBONI, Nério e ANDRADE, Rui Otávio Bernardes. Gestão de Cursos de Administração: metodologias e diretrizes curriculares. São Paulo: Prentice Hall, 2004.

BUFFA, Ester. NOSELLA, Paolo. Schola Mater. A Antiga Escola Normal de São Carlos. 1911-1933. São Carlos: EdUFSCar, 2002.

CONSELHO FEDERAL DE ADMINISTRAÇÃO. História da Profissão. Disponível em: http://www.cfa.org.br/administracao/historia-da-profissao. Acesso em 08 de agosto de 2.016 .

CORBUCCI, P. R. . O ensino superior brasileiro na década de 90. Políticas Sociais (IPEA) Brasília, v. 2, p. 105-109, 2001.

FUNDAÇÃO JOÃO PINHEIRO. Perfil de Minas Gerais. CBMM, 1999. Disponível em: http://portal.mec.gov.br/setec/arquivos/pdf/Indicadores\%20Scio-econmicos.pdf. Acesso em set. de 2018.

GATTI JR, Décio.; OLIVEIRA, Lúcia Helena M. M. História das Instituições Educativas: um novo olhar historiográfico. Cadernos de História da Educação, Uberlândia/MG, v. 1, n.1, p. 73-76, 2002. 
MAGALHÃES, Justino Pereira de. Tecendo Nexos: História das instituições educativas. Bragança Paulista: Editora Universitária São Francisco, 2004.

GONCALVES NETO, Wenceslau; MAGALHÃES, Justino Pereira. O local na História da Educação: o município pedagógico em Portugal e Brasil. In: Marta Maria de Araujo. (Org.). História(s) Comparada(s) da Educação. Brasília: Liber Livro Editora, 2009.

NÓVOA, Antônio. História da educação: percursos de uma disciplina. Análise Psicológica. Lisboa, Portugal, 1996. 417-434.

UNIVERSIDADE FEDERAL DE UBERLÂNDIA. Salário Mínimo Necessário (S.M.N.) dos Anos de $1991 \quad a \quad 2017 . \quad$ Disponível em Http://www.ie.ufu.br/sites/ie.ufu.br/files/Anexos/Bookpage/ CEPES_OP_SMN_Serie_Historica_Agregada_1991_2017_12.pdf. Acesso em setembro de 2018.

\section{Fontes documentais}

BRASIL. Lei $\mathrm{n}^{\circ}$ 5.540, de 28 de novembro de 1968. Fixa as normas de organização e funcionamento do ensino superior e sua articulação com a escola média, e dá outras providências.

BRASIL. Decreto 68.065, de 14 de janeiro de 1971. Regulamenta o Decreto-lei $n^{\circ}$ 869, de 12 de setembro de 1969, que dispõe sobre a inclusão da Educação Moral e Cívica como disciplina obrigatória, nas escolas de todos os graus e modalidades dos sistemas de ensino no País, e dá outras providências.

BRASIL. Secretaria Especial de Ação Comunitária da Presidência da República. ALENCAR, Geraldo. Ofício endereçado ao Diretor da Faculdade, 06 de outubro de 1986.

MEC- MINISTÉRIO DA EDUCAÇÃO. Novo Currículo Mínimo do Curso de Graduação em Administração. Parecer 433 de 05 de agosto de 1993.

MEC- MINISTERIO DA EDUCACAO E CULTURA. Resolução 15, de 29 de outubro de 1984. Fixa normas de autorização para funcionamento de cursos superiores de graduação e descrição de região Geo-Educacional.

MITRA ARQUIDIOCESANA DE DIAMANTINA. Regimento Institucional, aprovado pelo Parecer $\mathrm{n}^{\circ} 501$ de 03 de setembro de 1991.

MITRA ARQUIDIOCESANA DE DIAMANTINA. Relatório referente aos dados do vestibular do ano de 1991.1991.

MITRA ARQUIDIOCESANA DE DIAMANTINA. Relatório para Reconhecimento de Curso. 1994.

MITRA ARQUIDIOCESANA DE DIAMANTINA. Informações sobre os formandos da primeira turma. Caixa de Arquivos dos Formandos de 1995. 